\title{
Zur Kenntnis der Pepsinverdauung.
}

\author{
Von
}

stud. med. Paul Mey (Reval).

(Aus dem physiologischen Institat der Universität Marburg.)

(Der Redaktion zugegangen am 15. April 1906.)

Namentlich die Arbeiten von Lawrow ${ }^{1}$ ) und Zuntz ${ }^{2}$ ) haben gezeigt, daß entgegen der Theorie Kühnes die peptische Verdauung über die Bildung von Peptonen hinausgeht und im Laufe derselben biuretfreie Verdauungsprodukte von mehr oder weniger komplizierter Zusammensetzung entstehen. Die Darstellung derselben macht jedoch Schwierigkeiten, weil die Pepsinverdauung stets unvollkommen ist, so daß sich in den Verdauungsflüssigkeiten immer noch weniger veränderte Abbauprodukte des Eiweißes, wie Syntonin, Albumosen etc. nachweisen lassen, die bei der Verarbeitung der peptischen Verdauungsflüssigkeiten beträchtliche Hindernisse bereiten.

Nun haben kürzlich Kutscher und Lohmann ${ }^{8}$ ) bei der Papayotinverdauung, die insofern der Pepsinverdauung ähnlich ist, als es dabei auch nicht gelingt, die Biuretreaktion zum Verschwinden zu bringen, das Tannin benutzt, um die kolloidalen Bestandteile $z u$ beseitigen. Es ließ sich erwarten, daß die von Kutscher und Lohmann angewandte Methode sich mit Vorteil zum Studium der Pepsinverdauung verwerten lassen würde. Da sich sowohl das Eiweiß, wie die Albumosen und Peptone ${ }^{4}$ ) durch Tannin niederschlagen lassen sollen, hoffte ich mit

1) Diese Zeitschrift, Bd. XXVI, S. 513, und Bd. XXXIII, S. 312.

2) Diese Zeitschrift, Bd. XXVIII, S. 132.

3) Diese Zeitschrift, Bd. XLVI, S. 383.

4) Neumeister, Lehrb. d. phys. Chemie, II. Aufl., S. 234.

Hoppe-Seyler's Zeitschrift f. physiol. Chemie. XLVIII. 
Hilfe dieses Reagenses leicht zu den biuretfreien Verdauungsprodukten zu gelangen. Ich habe zwei dahingehende Versuche angestellt.

$\mathrm{Zu}$ Versuch I benutzte ich $83 \mathrm{~g}$ gut ausgepreßtes, frisches Fibrin, das in 1 l künstlichen Magensaft ${ }^{1}$ ) gebracht und 7 Tage bei $37^{\circ}$ C. im Brutschrank gehalten wurde.

In Versuch II überließ ich 16 g Hühnereiweiß in 21 künstlichem Magensaft 7 Tage der Verdauung. In beiden Versuchen prüfte ich die Verdauungsflüssigkeit nach der Vorschrift von Gürber täglich mit Günzburgs Reagens auf die Gegenwart freier Salzsäure.

Die Verarbeitung der Verdauungsflüssigkeiten geschah in beiden Fällen gleichmäßig. Die Flüssigkeiten wurden zunächst mit Natriumcarbonat versetzt, bis sie gegen Lackmuspapier ganz schwach alkalisch reagierten. Den dabei entstehenden Niederschlag saugte ich ab. Das klare Filtrat fällte ich mit Tanninlösung aus unter Vermeidung eines größeren Überschusses des Fällungsmittels. Die abgeschiedenen Tannate saugte ich ab und beseitigte im neuen Filtrate das überschüssige Tannin der Hauptsache nach durch Fällung mit Barytwasser. Das Filtrat vom Baryumtannat säuerte ich schwach mit Schwefelsäure an und trug Bleioxyd im Überschuß ein. Nach einiger Zeit nahm die häufig umgerührte Flüssigkeit alkalische Reaktion an. Nunmehr filtrierte ich das Baryumsulfat etc. ab und dampfte die Flüssigkeit unter Zugabe von etwas Bleioxyd ein. Die auf ein kleines Volumen gebrachte Flüssigkeit saugte ich vom Bleioxyd ab und engte sie zum Sirup ein, den ich mehrmals mit $96 \%$ igem Alkohol auskochte. Ungelöst zurück blieb dabei hauptsächlich anorganische Substanz, doch ließen sich in den Rückständen auch biuretgebende Körper nachweisen. Ich habe die Lösung derselben nur auf ihr Verhalten gegen Ammonsulfat näher geprüft. Sie ließen sich durch Ammonsulfat nicht abscheiden und müssen daher den echten Peptonen zugezählt werden. Die Hauptmasse der organischen Substanz war jedoch in Alkohol

1) Der künstliche Magensaft war aus der Schleimhaut eines Schweinemagens nach den Angaben von Thierfelder (Hoppe-Seylers Handbuch d. physiol u. pathol.-chemisch. Analyse, Aufl. 7, S. 382) dargestellt. 
löslich. Sie hinterblieb nach dem Verdunsten des Alkohols als wenig hygroskopischer, stark alkalisch reagierender Sirup.

In dem aus Versuch I stammenden alkohollöslichen Teil ließen sich noch merkliche Mengen Chlor, etwas Blei und Baryum und reichlich Natrium nachweisen, der im Versuch II gewonnene alkohollösliche Teil war frei von Chlor, Blei und Baryum, enthielt aber reichlich Natrium. Das Natrium schien in beiden Fällen an organische Verbindungen sauren Charakters geknüpft zu sein. In Versuch II habe ich den alkohollöslichen Rückstand bei $100^{\circ} \mathrm{C}$. getrocknet und gewogen, er wog 8,6 g. Mit diesen Rückständen habe ich noch folgende Reaktionen angestellt.

\section{Alkohollöslicher Rückstand von Versuch I.}

A. Farbenreaktionen.

1. Biuretreaktion, stark. Die Farbe, die bei dieser Reaktion erhalten wird, ist ein schönes, feuriges Rot, wie es nach Kühne für die Peptone charakteristisch sein soll.

2. Xanthoproteinreaktion, stark.

3. Millons Reaktion. Auf Zugabe von Millons Reagens zunächst weiße Fällung. Beim Erwärmen intensive Rötung der Flüssigkeit.

4. Reaktion nach Molisch, auffallend stark.

5. Reaktion nach Adamkiewicz, sehr intensiv.

6. Bromwasser gab gelben, reichlichen Niederschlag.

7. Schwefelreaktion, vollkommen negativ.

B. Fällungsreaktionen.

1. Bleizucker und Bleiessig, negativ.

2. Brückes Reagens + $\mathrm{HCl}$, schwache Trübung.

3. Salpetersäure, negativ.

4. Metaphosphorsäure, negativ.
Alkohollöslicher Rückstand von Versuch II.

A. Farbenreaktionen.

1. Biuretreaktion wie bei I.

2. Xanthoproteinreaktion, stark.

3. Millons Reaktion wie bei I.

4. Reaktion nach Molisch, schwach.

5. Reaktion nach Adamkiewicz, intensiv.

6. Bromwasser, wirkt wie bei I.

7. Schwefelreaktion, vollkommen negativ.

B. Fällungsreaktionen.

1. Bleizucker und Bleiessig, gaben starke, in Essigsäure lösliche Fällungen.

2. Brückes Reagens wirkt wie bei I.

3. Salpetersäure, negativ.

4. Metaphosphorsäure, negativ. 
5. Phosphorwolframsäure, reichlicher Niederschlag. Beim Erhitzen läuft die Hauptmasse zu einem Öl zusammen, das in Wasser unlöslich ist. Der in Lösung gegangene Teil scheidet sich beim Erkalten krystallinisch ab.

6. Esbachs Reagens, nach einiger Zeit geringe Trübung.

7. Tannin, negativ.

8. Ferrocyankalium + Essigsäure, negativ.

9. Sättigung mit Ammonsulfat erzeugt in einer konzentrierten Lösung nur eine ganz schwache Trübung.
5. Phosphorwolframsäure wirkt wie bei I.

6. Esbachs Reagens, nach einiger Zeit Trübung.

7. Tannin, negativ.

8. Ferrocyankalium + Essigsäure, negativ.

9. Sättigung mit Ammonsulfat erzeugt in einer sehr konzentrierten Lösung nur eine Trübung, aber keinen Niederschlag.

Meine Versuche zeigen, daß man mit Hilfe der Tanninmethode die bei der Pepsinverdauung gebildeten Albumosen bis auf Spuren beseitigen kann. Dagegen scheinen bei der Pepsinverdauung auch reichliche Mengen peptonartiger Körper, die mit Tannin keine schwerlöslichen Verbindungen eingehen und daher durch dieses Fällungsmittel sich nicht entfernen lassen, $z u$ entstehen. 